\title{
Resistance of Rosa Species and Cultivars to Pratylenchus penetrans
}

\author{
Yunliang Peng', Wanrong Chen ${ }^{1}$, and Maurice Moens ${ }^{2}$ \\ Department of Crop Protection, Agricultural Research Center, Burg. Van \\ Gansberghelaan 96, Merelbeke B-9820, Belgium
}

Additional index words. host suitability, multiplication factor, root-lesion nematode, Rosa corymbifera 'Laxa', $R$. canina 'Pollmeriana', $R$. laevigata anemoides, $R$. virginiana, $\mathrm{Pf} / \mathrm{Pi}$

\begin{abstract}
Methods to screen for resistance to root-lesion nematode Pratylenchus penetrans in Rosa were modified to screen-rooted materials. Sixty days after rooting, plants were transplanted into $50-\mathrm{mL}$ pots filled with river sand and each inoculated with $500 P$. penetrans in $400 \mu \mathrm{L}$ water 10 days later. The inoculated plants were fertilized weekly and incubated in a growth chamber or a greenhouse for 5 months when nematodes were extracted from the sand and root system and enumerated. When used for screening of the 131 Rosa accessions, this approach allowed the observation of a large variation in host suitability. While a majority of the accessions supported the multiplication of $P$. penetrans, previously reported resistance of $R$. multiflora 'K1' and $R$. virginiana to $P$. penetrans was confirmed. Rosa laevigata anemoides allowed a significantly lower nematode multiplication than the currently prevalent rootstock $R$. corymbifera 'Laxa'.
\end{abstract}

The root-lesion nematode, Pratylenchus penetrans (Cobb, 1917) Filip'jev \& Schuurmans Stekhoven, 1941, is a biotrophic plant parasite on a wide range of hosts mainly in temperate climates. It is one of the principal nematode species infecting ornamental plants. The nematode causes destruction of the root system, which results in loss of vigor in young plants. Serious losses in roses caused by $P$. penetrans were reported in California (Sher, 1959), Canada (Johnson and McClannahan, 1974), Japan (Ohkawa and Saigusa, 1981), and Europe (Coolen and D'Herde, 1970; Coolen and Hendrickx, 1972; Corbett, 1973).

Satisfactory control of $P$. penetrans in the field is achieved by the application of fumigant or non-fumigant nematicides (Corbett, 1973; Richardson and Grewal, 1993). However, increasing concern about environmental contamination stimulates the use of alternative control strategies that make use of resistance and tolerance of species and cultivars (Dubois et al., 1990; Horst, 1983). Resistance and susceptibility relate to nematode reproduction, whereas tolerance describes host injury (Cook and Evans, 1987). Plants that are resistant (support fewer nematodes) or are tolerant (do not exhibit growth reduction) improve nematode management and crop development. The extractable population density in soil and roots of infected plants at the end of the growing season $(\mathrm{Pf})$ and its ratio $(\mathrm{Pf} / \mathrm{Pi})$ to the initial population density $(\mathrm{Pi})$ of nematodes are common measurements for comparison of host suitability of plants (Westcott and Zehr, 1991). Accessions

Received for publication 14 Jan. 2002. Accepted for publication 5 Dec. 2002.

${ }^{1}$ On study leave from Institute of Plant Protection, Sichuan Academy of Agricultural Sciences, Jinjusi Road 20, Chengdu 610066, China.

${ }^{2}$ Also affiliated with Laboratory for Agrozoology, Univ. of Gent, Coupure 555, 9000 Gent, Belgium. To whom reprint requests should be sent. E-mail address:m.moens@clo.fgov.be. with $\mathrm{Pf} / \mathrm{Pi}$ ratio less than one are considered resistant in that they do not support nematode reproduction. Measurements of plant growth characters are indicators of tolerance (Cook and Evans, 1987).

Resistance and tolerance to nematodes have been important components in a few rose screening and breeding programs (Dubois et al., 1990; Horst, 1983). Rosa eglanteria (syn. $R$. rubiginosa) and $R$. chinensis 'Major' were found to be the least suitable Rosa hosts of $P$. penetrans (Coolen and Hendrickx, 1972; Ohkawa and Saigusa, 1981). In a previous study, we detected partial resistance to $P$. penetrans in $R$. virginiana, which supported significantly lower multiplication of the nematode than the control cultivar $R$. corymbifera 'Laxa' (Peng and Moens, 2002a). In the present study, we evaluated the host suitability of 131 accessions of Rosa sp. for P. penetrans.

\section{Materials and Methods}

Inoculum preparation. The population of $P$. penetrans used in this study was isolated in a mist chamber (Seinhorst, 1950) from maize roots collected in a field at Lokeren, Belgium. Traditional species identification using morphology and morphometrics was confirmed with rDNA-RFLP patterns compared to those obtained by Waeyenberge et al. (2000). Isolated nematodes were sterilized with a mixture of malachite green and streptomycin sulfate for 10 min (Peng and Moens, 1999) and were cultured monoxenically on carrot disks (O'Bannon and Taylor, 1969) for 70-75 d. After that period they were extracted from the carrot disks during 1 week in the mist chamber and collected as inoculum. The adult to juvenile ratio of the inoculum varied between 1 and 1.2. The sequence of extraction, sterilization, and culturing on carrot disks was repeated to build up and to maintain the nematode population. The isolate used in this study was shown to be pathogenic on Rosa after its inoculation on seedlings of Rosa corymbifera 'Laxa' (Peng and Moens, 2002b).

Determination ofoptimuminoculation density. Optimum inoculation density was identified in an experiment conducted in a growth chamber. Fifty-day-old plants of the known susceptible standard $R$. corymbifera 'Laxa' were transplanted into $50-\mathrm{mL}$ pots filled with sand (sizes between 150-212 $\mu \mathrm{m}$ ) and amended with $27.75 \mathrm{mg} \cdot \mathrm{mL}^{-1}$ soluble composed fertilizer M77 (Scotts, The Netherlands) according to Peng and Moens (2002a) and subjected to a 12-h photoperiod and temperature and relative humidity set at $22^{\circ} \mathrm{C}$ and $85 \%$ during the light and $20{ }^{\circ} \mathrm{C}$ and $80 \%$ during the dark. Ten days later they were inoculated at their base with $125,250,500$, or 1000 mobile stages including larvae and adults of $P$. penetrans that had passed through the filter paper placed under the carrot disks in the mistifier chamber. Nematodes were inoculated in $400 \mu \mathrm{L}$ water. Plants were placed in a completely randomized design; each treatment was replicated 8 to 10 times. Each week, every pot was watered $(10 \mathrm{~mL})$ twice and fertilized once $(10 \mathrm{~mL})$ with $7.5 \mathrm{mg} \cdot \mathrm{mL}^{-1}$ M77 fertilizer. Fifty days after inoculation, $P$. penetrans density was determined separately in the sand and the roots. Roots were cut into $1-2 \mathrm{~cm}$ fragments and macerated in $500 \mathrm{~mL}$ water in a Waring blender for $90 \mathrm{~s}$. Nematodes were extracted from both the obtained nematode-root suspension or the sand with a fully automated nematode extractor based on centrifugation (Hendrickx, 1995). All the nematodes in the $10 \mathrm{~mL}$ extract were counted under a dissecting microscope.

Plant material. A total of 131 accessions of Rosa was obtained from different sources (Table 1). The collection was composed of 29 tea or hybrid tea rose cultivars, 11 floribunda roses, 9 hybrid musk roses, 7 shrub roses, 23 other modern roses, 35 accessions of a total of 24 botanical Rosa species or subspecies, and 17 other old garden roses. The accessions were classified according to the American Rose Society (ARS) Approved Horticultural Classification (Liberta and Young, 2000). The rootstocks $R$. corymbifera 'Laxa' and $R$. canina 'Pollmeriana' ( $\mathrm{Pf} / \mathrm{Pi}=15.8$ and 24.2, respectively) were added as standards with known susceptibility.

As seeds were not available for the majority of the screened accessions, each accession was propagated by dipping hardwood cuttings (two leaves) in a mixture of active carbon and 2000 ppm IBA and planted in a shaded greenhouse in a 1 peat : 1 sand $(\mathrm{v} / \mathrm{v})$ mixture previously pasteurized with steam at $80{ }^{\circ} \mathrm{C}$ in late June. Forty days later, the majority of the plants were successfully rooted. After another $20 \mathrm{~d}$, the rooted plants with 3-4 roots and 4-6 new leaves were uprooted. The peat was washed off and plants were transplanted singly into 50-mL plastic pots (see above).

Screening. From Aug. 1998 to Jan. 1999, plants of 59 accessions were screened in a growth chamber (conditions as above). From Aug. 1999 to Jan. 2000, another 72 accessions were screened in the greenhouse $\left(20\right.$ to $22^{\circ} \mathrm{C}$ ) along with 'Barcarolle', 'Pailine Sport', 'Pink Prosperity', 'Rose Romantic', and R. laevigata 
Table 1. Host reaction of Rosa accessions to Pratylenchus penetrans 5 months after inoculation with 500 nematodes in $400 \mu \mathrm{L}$ water in the $1998-2000$ screening.

\begin{tabular}{|c|c|c|c|c|c|c|c|c|}
\hline \multirow[b]{2}{*}{ Rosa accessions } & \multirow[b]{2}{*}{ Breeder } & \multirow[b]{2}{*}{ Group $^{2}$} & \multirow[b]{2}{*}{ Source ${ }^{y}$} & \multirow[b]{2}{*}{$\mathrm{n}$} & \multirow[b]{2}{*}{$\begin{array}{c}\mathrm{Pf} / \mathrm{Pi} \\
\text { mean }\end{array}$} & \multicolumn{2}{|c|}{ Difference in $\mathrm{Pf} / \mathrm{Pi}$} & \multirow{2}{*}{$\begin{array}{c}\text { Maximum Pf/Pi } \\
\text { in one of the } \\
\text { three replicates }\end{array}$} \\
\hline & & & & & & $\begin{array}{l}\text { Within } \\
\text { groups }^{\mathrm{x}}\end{array}$ & $\begin{array}{l}\text { Between all } \\
\text { accessions }^{w}\end{array}$ & \\
\hline Barcarolle & Laperriére, 1959 & HT MR & DPGB & 5 & 1.49 & $\mathrm{~A}$ & $\mathrm{a}$ & 3.42 \\
\hline Aruba & Spek, 1996 & HT MR & DPGB & 3 & 1.69 & A & a & 4.04 \\
\hline G.D. Jardins de Bagatelle & de Bagatelle, 1986 & HT MR & DPGB & 3 & 1.89 & A & $\mathrm{ab}$ & 5.06 \\
\hline Red Unique & & HT MR & DPGB & 3 & 1.95 & $\mathrm{~A}$ & $\mathrm{ab}$ & 3.04 \\
\hline Frederyk Chopin & Zyla, 1973 & HT MR & DPGB & 3 & 2.27 & A & $a b$ & 4.04 \\
\hline Pavarotti & deRuiter, 1993 & HT MR & DPGB & 3 & 2.38 & A & $a b$ & 2.76 \\
\hline Dame de Coeur & Lens, 1958 & HT MR & DPGB & 3 & 2.47 & A & $a b$ & 4.78 \\
\hline Pailine Sport & RvS-Melle, 1989 & HT MR & DPGB & 7 & 2.49 & A & $a b$ & 7.24 \\
\hline Velvet Fragrance & Fryer's Nursery Ltd., 1988 & HT MR & DPGB & 3 & 2.97 & A & $a b$ & 4.28 \\
\hline Isabelle & RvS-Melle, 1989 & HT MR & DPGB & 3 & 3.07 & A & $\mathrm{ab}$ & 4.54 \\
\hline Christine & McGredy, 1918 & HT MR & DPGB & 3 & 3.09 & A & $\mathrm{ab}$ & 3.96 \\
\hline Rossini & & HT MR & DPGB & 3 & 3.66 & A & $a-c$ & 5.04 \\
\hline Gypsy Curiosa & & HT MR & DPGB & 3 & 3.97 & $\mathrm{AB}$ & $\mathrm{a}-\mathrm{c}$ & 6.74 \\
\hline Inka & Tantau, 1978 & HT MR & DPGB & 3 & 4.01 & $\mathrm{AB}$ & $a-c$ & 5.42 \\
\hline Dream & Dramm, 1938 & HT MR & DPGB & 3 & 4.03 & $\mathrm{AB}$ & $\mathrm{a}-\mathrm{c}$ & 6.24 \\
\hline Limona & Kordes, 1993 & HT MR & DPGB & 3 & 4.17 & $\mathrm{AB}$ & $a-c$ & 8.44 \\
\hline Josée & RvS-Melle, 1987 & HT MR & DPGB & 3 & 5.07 & $\mathrm{AB}$ & $a-c$ & 5.22 \\
\hline Orange Unique & & HT MR & DPGB & 3 & 5.67 & $\mathrm{AB}$ & $a-c$ & 12.78 \\
\hline Gomery & RvS-Melle, 1985 & HT MR & DPGB & 3 & 5.77 & $\mathrm{AB}$ & $a-c$ & 7.36 \\
\hline Verosa & & HT MR & DPGB & 3 & 5.83 & $\mathrm{AB}$ & $a-c$ & 6.50 \\
\hline Texas & Kordes, 1993 & HT MR & DPGB & 3 & 5.91 & $\mathrm{AB}$ & $a-c$ & 6.44 \\
\hline Kiss & & HT MR & DPGB & 3 & 5.97 & $\mathrm{AB}$ & $\mathrm{a}-\mathrm{c}$ & 11.50 \\
\hline Pascali & Lens, A. Dickson, 1963 & HT MR & DPGB & 3 & 6.11 & $\mathrm{AB}$ & $a-c$ & 9.36 \\
\hline Auguste Renoir & Meilland, A. A., 1992 & HT MR & DPGB & 3 & 7.38 & $\mathrm{~A}-\mathrm{C}$ & $\mathrm{a}-\mathrm{c}$ & 11.34 \\
\hline Helena & RvS-Melle, 1988 & HT MR & DPGB & 3 & 8.53 & $\mathrm{~A}-\mathrm{C}$ & $a-c$ & 12.48 \\
\hline Sweet Shot & & HT MR & DPGB & 3 & 8.97 & $\mathrm{ABC}$ & $a-c$ & 16.12 \\
\hline Madelon & de Ruiter, G., 1987 & HT MR & DPGB & 3 & 13.74 & $\mathrm{BC}$ & $\mathrm{a}-\mathrm{c}$ & 17.02 \\
\hline Red Calypso & & HT MR & DPGB & 4 & 17.00 & $\mathrm{C}$ & $a-f$ & 23.88 \\
\hline Katrien & RvS-Melle, 1990 & HT MR & DPGB & 3 & 32.76 & $\mathrm{D}$ & $\mathrm{e}-\mathrm{g}$ & 35.56 \\
\hline Ville du Rœulx & RvS-Melle, 1989 & F MR & DPGB & 5 & 1.64 & $\mathrm{~A}$ & $\mathrm{a}$ & 3.48 \\
\hline Mercedes & Kordes, R., 1974 & F MR & DPGB & 3 & 2.30 & $\mathrm{AB}$ & $a b$ & 5.66 \\
\hline Rose Romantic & Kordes, 1984 & F MR & DPGB & 12 & 2.83 & $\mathrm{AB}$ & $a b$ & 8.14 \\
\hline Modern Fire & & F MR & DPGB & 3 & 2.99 & $\mathrm{AB}$ & $\mathrm{ab}$ & 4.02 \\
\hline Floranje & RvS-Melle, 1985 & F MR & DPGB & 4 & 4.30 & $\mathrm{AB}$ & $a-c$ & 6.84 \\
\hline Miracle & Verbeek, 1962 & F MR & DPGB & 3 & 4.37 & $\mathrm{AB}$ & $a-c$ & 5.38 \\
\hline Red Velvet & Kordes, 1940 & F MR & DPGB & 3 & 5.85 & $\mathrm{AB}$ & $\mathrm{a}-\mathrm{c}$ & 7.50 \\
\hline Gaetane & RvS-Melle, 1985 & F MR & DPGB & 3 & 7.75 & $\mathrm{AB}$ & $a-c$ & 9.46 \\
\hline Bonica & Meilland, F., 1958 & F MR & DPGB & 3 & 9.81 & $\mathrm{~A}-\mathrm{C}$ & $\mathrm{a}-\mathrm{c}$ & 13.06 \\
\hline Vanilla & Kordes, 1994 & F MR & DPGB & 4 & 12.05 & $\mathrm{BC}$ & $\mathrm{a}-\mathrm{e}$ & 20.26 \\
\hline Melglory & RvS-Melle, 1982 & F MR & DPGB & 3 & 19.39 & $\mathrm{C}$ & $a-f$ & 28.24 \\
\hline Pink Prosperity & Bentall, 1931 & HMsk MR & DPGB & 8 & 1.81 & A & $\mathrm{a}$ & 6.01 \\
\hline Lavender Lassie & Kordes, 1960 & HMsk MR & DPGB & 5 & 2.05 & A & $a b$ & 3.93 \\
\hline Felicia & Pemberton, 1928 & HMsk MR & DPGB & 3 & 3.19 & $\mathrm{~A}$ & $a-c$ & 4.52 \\
\hline Plaisanterie & Lens, 1996 & HMsk MR & DPGB & 3 & 3.23 & A & $a-c$ & 5.78 \\
\hline Diamond Rose & Lens, 1995 & HMsk MR & DPGB & 3 & 5.97 & A & $a-c$ & 9.86 \\
\hline Ravel & Lens, 1987 & HMsk MR & DPGB & 4 & 6.43 & A & $a-c$ & 8.70 \\
\hline Jacqueline Humery & Lens, 1995 & HMsk & DPGB & 3 & 6.75 & $\mathrm{~A}$ & $\mathrm{a}-\mathrm{c}$ & 9.46 \\
\hline Moonlight & Pemberton, 1913 & HMsk MR & DPGB & 3 & 6.82 & $\mathrm{~A}$ & $a-c$ & 7.86 \\
\hline Mozart & P. Lambert, 1937 & HMsk MR & DPGB & 6 & 7.68 & $\mathrm{~A}$ & $\mathrm{a}-\mathrm{c}$ & 11.52 \\
\hline Carmenetta & Central Exp. Farm, 1923 & S MR & DPGB & 3 & 2.16 & A & $\mathrm{ab}$ & 2.65 \\
\hline William Shakespeare & Austin, David, 1987 & S MR & DPGB & 3 & 2.31 & A & $a b$ & 2.46 \\
\hline Fredica & INRA, 1974 & S MR & INRA & 3 & 2.59 & A & $\mathrm{ab}$ & 4.88 \\
\hline Rush & Lens, 1983 & S MR & DPGB & 3 & 3.97 & A & $a-c$ & 5.90 \\
\hline Heidtraum & Noack, W., 1991 & S MR & DPGB & 3 & 5.26 & $\mathrm{AB}$ & $\mathrm{a}-\mathrm{c}$ & 7.16 \\
\hline Graham Thomas & Austin, David, 1983 & S MR & DPGB & 6 & 5.39 & $\mathrm{AB}$ & $a-c$ & 6.92 \\
\hline Red Wing & & S MR & DPGB & 3 & 15.99 & $\mathrm{~B}$ & $\mathrm{a}-\mathrm{e}$ & 18.69 \\
\hline$\times 8914$ & Lens, 1989 & MR & DPGB & 4 & 1.74 & A & a & 3.71 \\
\hline Pink Surprise & Lens, 1980 & Min MR & DPGB & 3 & 1.93 & A & $a b$ & 3.46 \\
\hline Flash & Hatton, 1938 & LCl MR & DPGB & 3 & 1.95 & A & $a b$ & 3.28 \\
\hline$\times 8843$ & Lens, 1988 & MR & DPGB & 6 & 2.27 & $\mathrm{~A}$ & $\mathrm{ab}$ & 4.34 \\
\hline Swany & Meilland, Mrs. Marie-Louis, 1978 & Min MR & DPGB & 3 & 2.54 & $\mathrm{~A}$ & $\mathrm{ab}$ & 6.71 \\
\hline Lena & Dickson, R., 1906 & T MR & DPGB & 3 & 2.55 & A & $a b$ & 4.58 \\
\hline Enigma & & MR & DPGB & 3 & 3.17 & $\mathrm{~A}$ & $\mathrm{ab}$ & 3.58 \\
\hline New Dawn Somerset & Somerset Rose Nursery, 1930 & $\mathrm{LCl} \mathrm{MR}$ & DPGB & 3 & 3.20 & $\mathrm{~A}$ & $\mathrm{a}-\mathrm{c}$ & 6.31 \\
\hline Max Graf & Bowditch, 1919 & HRg MR & DPGB & 3 & 3.67 & A & $\mathrm{a}-\mathrm{c}$ & 12.08 \\
\hline Dr Huey & Thomas, 1914 & $\mathrm{LCl} \mathrm{MR}$ & INRA & 3 & 3.94 & A & $a-c$ & 5.34 \\
\hline Veilchenblau & Schmidt, J.C., 1909 & HMult MR & DPGB & 3 & 4.29 & A & $\mathrm{a}-\mathrm{c}$ & 5.77 \\
\hline Prairie & & MR & DPGB & 3 & 4.56 & A & $a-c$ & 6.78 \\
\hline Marstem & & MR & INRA & 3 & 5.10 & A & $a-c$ & 11.60 \\
\hline Kathleen Harrop & Dickson, A., 1919 & B MR & DPGB & 3 & 6.20 & A & $\mathrm{a}-\mathrm{c}$ & 7.96 \\
\hline
\end{tabular}

continued on next page. 


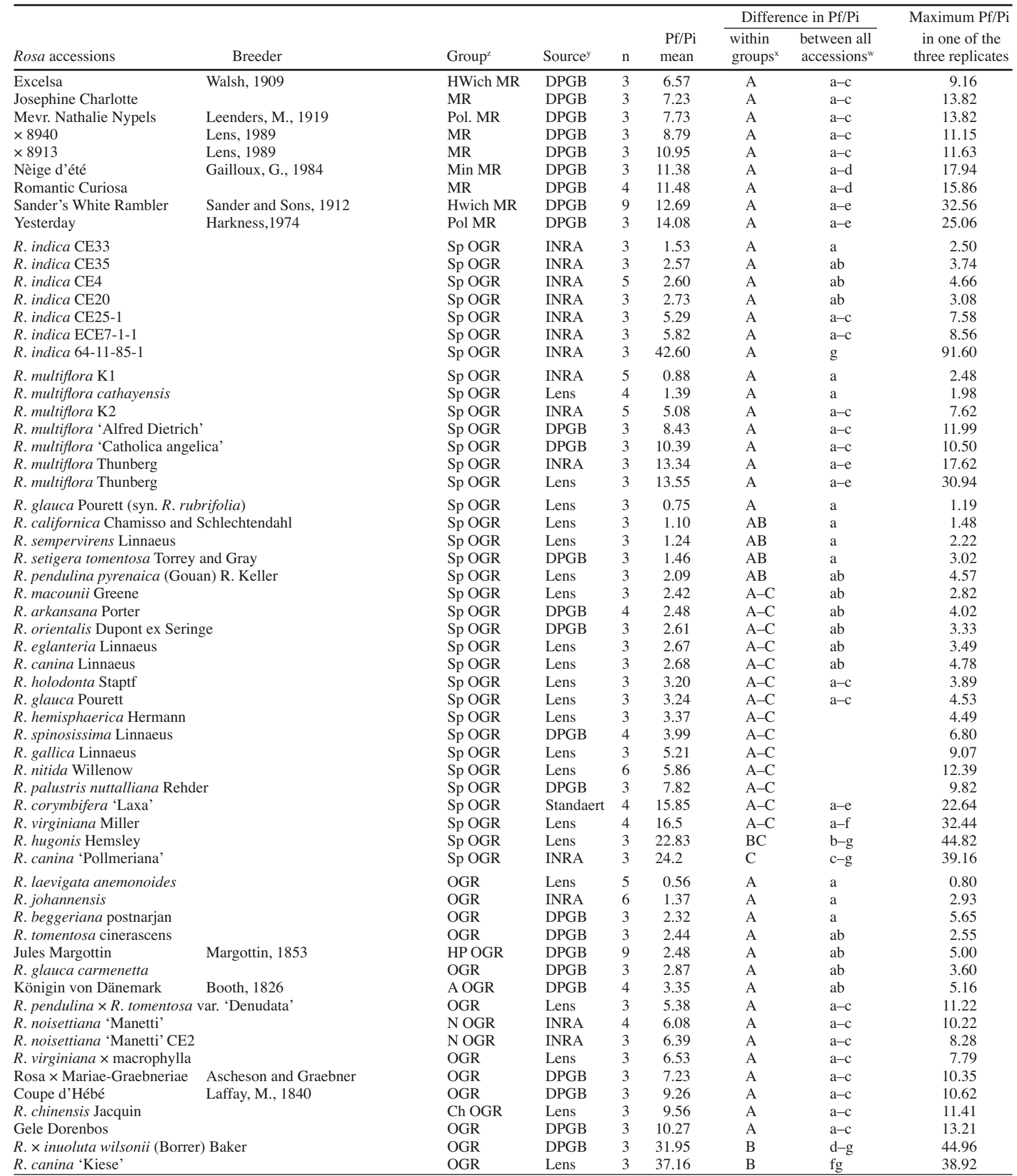

${ }^{2}$ Accessions classified according to the American Rose Society (ARS) Approved Horticultural Classification (Liberta and Young, 2000) grouping accessions as Hybrid Tea (HT), Floribunda (F), Hybrid Musk (HMsk), Shrubs (S), or other modern roses (MR) including large-flowered climbers (LCl), Hybrid Wichurana (HWhich), Bourbon (B), Tea (T), Hybrid Rugosa (HRg), Polyantha (Pol), Miniature (M), and Hybrid Multiflora (Hmult), Other accessions are botanical species or subspecies (Sp.) or other old garden roses (OGR) including Hybrid Perpetual (HP), Alba (A), China (Ch), and Noisetta (N).

${ }^{y}$ DPGB: Dept. of Plant Genetics and Breeding, Agricultural Research Centre, Melle, Belgium. INRA: Station de Fréjus, Fréjus, France. Lens : Nurseries Louis Lens, Oudenburg, Belgium, Standaert: Standaert Nurseries, Brugge, Belgium.

${ }^{x}$ Means of accessions of a same species group followed by a common character are not significantly different according to Tukey honest difference (THD) test for unequal $\mathrm{N}(P<0.05)$.

${ }^{w}$ Means followed by an overlapping alphabetic interval are not significantly different when accessions were compared altogether using THD test for unequal $\mathrm{N}$ $(P<0.05)$. 
anemonoides, all accessions with a $\mathrm{Pf} / \mathrm{Pi}<1.0$ during the 1998-99 screening, as well as with the randomly selected accession 'Jules Magrottin'. In the greenhouse, $4 \mathrm{~h}$ of supplemental illumination were applied in winter.

For each accession, three to five plants were screened with 500 mobile stages of $P$. penetrans in $400 \mu \mathrm{L}$ water (see above). They were placed in a completely randomized design, and fertilized and watered as described above. Five months after their inoculation, nematodes were extracted from the sand and the root system and counted separately (see optimum inoculation density).

The resistance of $R$. laevigata anemoides on which $P$. penetrans did not multiply $(\mathrm{Pf} / \mathrm{Pi}$ averaged at 0.80 ) in the 2 years of screening was confirmed in a 0.5 -L pot experiment in 2001. In mid-Sept. 2000, plants of R. laevigata anemoides were rooted as above, transplanted into 0.5 -L pots filled with sand and inoculated with 500 mobile stages of $P$. penetrans in 400 $\mu \mathrm{L}$ water $10 \mathrm{~d}$ after transplanting in early Dec. 2000. Plants of $R$. virginiana and $R$. corymbifera 'Laxa' were infested similarly for comparison. Fifty milliliters of $7.5 \mathrm{mg} \cdot \mathrm{mL}^{-1}$ M77 were applied once, and $50 \mathrm{~mL}$ water twice every week to each plant. Nematodes were extracted (see above) and counted after 5 months of incubation in the air-conditioned greenhouse.

Statistics. For all of the experiments, Pf was calculated as the sum of numbers of nematode (including eggs) extracted from both sand and roots. The $t$ test and ANOVA analysis were performed with the Statistica software package (StatSoft, 1999). Tukey honest difference (THD) test for unequal $\mathrm{N}$ (Spjotvoll/Stoline test) was used to compare the means $(P=0.05)$.

\section{Results}

Optimum inoculation density. Final nematode population on $R$. corymbifera 'Laxa' was inoculum density dependent $(F=13.03, P<$ $0.0001)$. The differences in $\mathrm{Pf} / \mathrm{Pi}$, however, were nonsignificant between the tested inoculum levels (Table 2). The standard deviation on the $\mathrm{Pf} / \mathrm{Pi}$ averages was least at $\mathrm{Pi}=500$, which was then used during the screening.

Effects of accession on P. penetrans multiplication. During both screening periods, significant effects of the accessions on the multiplication of $P$. penetrans were observed $(F=4.88, P<0.0001$; and $F=3.81, P<0.0001$, during 1998-99 and 1999-2000, respectively). However, significant effects of screening times

Table 2. Multiplication of Pratylenchus penetrans at $50 \mathrm{~d}$ postinoculation in rooted plants of Rosa corymbifera 'Laxa' grown in sand in the growth chamber.

\begin{tabular}{lccc}
\hline $\mathrm{Pi}$ & $\mathrm{Pf}^{\iota}$ & $\mathrm{Pf} / \mathrm{Pi}$ & SD of Pf/Pi \\
\hline 125 & $609 \mathrm{a}$ & $4.87 \mathrm{a}$ & 2.52 \\
250 & $993 \mathrm{ab}$ & $3.97 \mathrm{a}$ & 2.00 \\
500 & $1961 \mathrm{bc}$ & $3.92 \mathrm{a}$ & 1.12 \\
1000 & $2731 \mathrm{c}$ & $2.73 \mathrm{a}$ & 1.44 \\
\hline
\end{tabular}

${ }^{2}$ Means in a column followed by the same letter are not significantly different according to Tukey honest difference test $(P<0.05)$. on the nematode multiplication were not observed $(\mathrm{F}=0.0077, P=0.9299)$. Consequently, the screening data obtained during both periods were pooled and mutually compared; the result of this comparison was similar to those obtained when the data of each period were analyzed separately (data not shown).

Out of the 131 screened accessions, only 14 scored a $\mathrm{Pf} / \mathrm{Pi} \leq 1.81$, smaller than the $\mathrm{Pf} / \mathrm{Pi}$ on $R$. canina 'Pollmeriana' $(\mathrm{Pf} / \mathrm{Pi}=24.20)$. No accession had a $\mathrm{Pf} / \mathrm{Pi}$ smaller than the $\mathrm{Pf} / \mathrm{Pi}$ obtained for the susceptible rootstocks $R$. corymbifera 'Laxa' $(\mathrm{Pf} / \mathrm{Pi}=15.85)$ (Table 1$)$. Conversely, two accessions, $R$. canina Kiese $(\mathrm{Pf} / \mathrm{Pi}=37.16)$ and $R$. indica $64-11-85-1(\mathrm{Pf} / \mathrm{Pi}$ $=42.60)$, supported greater nematode multiplication than $R$. corymbifera 'Laxa', but no accession allowed better nematode multiplication than $R$. canina 'Pollmeriana'.

Hybrid tea roses. All 29 tested cultivars supported multiplication of $P$. penetrans. The smallest multiplication was obtained on 'Barcarolle' (1.49). However, the Pf/Pi of 26 accessions did not differ from the $\mathrm{Pf} / \mathrm{Pi}$ on this latter cultivar. Nematode reproduction obtained on 'Katrien' (32.76) was higher than on all other screened hybrid tea roses. The maximum $\mathrm{Pf} / \mathrm{Pi}$ varied between 2.76 ('Pavarotti') and 35.56 ('Katrien').

Floribunda roses. P. penetrans multiplied well on all of the 11 screened hybrids. The Pf/Pi varied between 1.64 ('Ville de Rœulx') and 19.39 ('Melglory'). Only on the latter cultivar and on 'Vanilla' $(\mathrm{Pf} / \mathrm{Pi}=12.05)$ did the nematodes multiply better than on 'Ville de Rœulx'.

Hybrid musk roses. The lowest multiplication was observed on 'Pink Prosperity' (1.81), the greatest on 'Mozart' (7.68). Maximum Pf/Pi values varied between 3.93 ('Lavender Lassie') and 11.52 ('Mozart').

Shrub roses. The Pf/Pi on four out of seven tested shrub roses varied between 2.3 ('William Shakespeare') and 5.96 ('Rush') and was less than on 'Red Wing' $(\mathrm{Pf} / \mathrm{Pi}=15.99)$, which also showed the greatest maximum $(\mathrm{Pf} / \mathrm{Pi}=$ 18.69).

Other modern roses. The average $\mathrm{Pf} / \mathrm{Pi}$ obtained on modern roses other than hybrid tea, floribunda, hybrid musks and shrubs, was situated between 1.74 (' $\times$ 8914') and 14.08 ('Yesterday'). On 'Sander's White Rambler', the maximum Pf/Pi reached 32.56; the smallest value for the maximum $\mathrm{Pf} / \mathrm{Pi}$ was observed on 'Flash' (3.28).

Rosa multiflora and R. indica. No significant differences in nematode multiplication were observed after multiple comparison of the accessions within the species, although varia- tions were observed among these accessions. Rosa multiflora 'K1' did not allow nematode reproduction $(\mathrm{Pf} / \mathrm{Pi}=0.88)$ whereas on other accessions of this species great reproduction factors were registered (e.g., R. multiflora 'Alfred Dietrich' and 'Catholica Angelica'). The majority of the accessions of $R$. indica allowed medium nematode multiplication, the $\mathrm{Pf} / \mathrm{Pi}$ observed on $R$. indica $64-11-85-1$ was extremely large (42.60). In one of the replicates of this accession, a $\mathrm{Pf} / \mathrm{Pi}=91.6$ was scored.

Rosa species and subspecies other than $R$. multiflora and $R$. indica. One accession of $R$. glauca (syn. $R$. rubrifolia) did not support $P$. penetrans reproduction $(\mathrm{Pf} / \mathrm{Pi}=0.75)$. Another accession from the same nursery, however, did support nematode multiplication $(\mathrm{Pf} / \mathrm{Pi}=3.24)$. Poor multiplication of the nematode was also observed on $R$. californica, $R$. sempervirens, $R$. setigera tomentosa, and $P$.pendulinapyrenaica $(\mathrm{Pf} / \mathrm{Pi}=1.10-2.09)$ and good multiplication was observed on $R$. canina 'Pollmeriana'. The reproduction factor on $R$. virginiana did not differ from the Pf/Pi obtained on $R$. corymbifera 'Laxa' and $R$. canina 'Pollmeriana'. The maximum $\mathrm{Pf} / \mathrm{Pi}$ in these accessions varied between 1.19 and 44.82 .

Other old garden roses. Nematode multiplication devided the other tested old garden roses in two catogories. Pratylenchus penetrans did not multiply in any of the five replicates of $R$. laevigata anemoides (average $\mathrm{Pf} / \mathrm{Pi}=0.56$ ) whereas very high nematode multiplication was observed on $R$. xinuoluta wilsonii $(\mathrm{Pf} / \mathrm{Pi}$ $=31.95$ and $R$. canina 'Kiese' $(\mathrm{Pf} / \mathrm{Pi}=37.16)$. Other accessions supported the multiplication of nematodes, which was not different from that on $R$. laevigata anemoides.

In the experiment comparing the host suitability of $R$. laevigata anemoides, $R$. corymbifera 'Laxa', and $R$. virginiana in 0.5 -L pots, the difference in multiplication of $P$. penetrans was significant $(F=45.35, P<$ $0.0001)$. The $\mathrm{Pf} / \mathrm{Pi}$ on $R$. laevigata anemoides averaged 1.89 and was lower than that of $R$. corymbifera 'Laxa' but similar to that of $R$. virginiana (Table 3 ).

\section{Discussion}

Because cultural conditions can greatly influence the growth of plants on one hand and the survival, development and reproduction of nematodes on the other hand, it is necessary to conduct resistance-screening experiments in carefully defined conditions. In previous research we determined optimal conditions for screening of the host suitability of seed propagated Rosa species and cultivars to $P$.

Table 3. Multiplication of 500 mobile stages of Pratylenchus penetrans 5 months after inoculation in $400 \mu \mathrm{L}$ water onto Rosa species grown in sand (Dec. 2000-May 2001).

\begin{tabular}{lccc}
\hline & & \multicolumn{1}{c}{$\mathrm{Pf} / \mathrm{Pi}$} \\
\cline { 3 - 4 } Accessions & $\mathrm{N}^{\mathrm{z}}$ & Mean $^{\mathrm{y}}$ & $95 \%$ confidence interval \\
\hline Rosa laevigata anemoides & 18 & $1.89 \mathrm{a}$ & $1.37-2.41$ \\
$R$. virginiana & 10 & $2.69 \mathrm{a}$ & $1.65-3.73$ \\
$R$. corymbifera 'Laxa & 13 & $19.74 \mathrm{~b}$ & $13.92-23.55$ \\
\hline${ }^{\mathrm{z}} \mathrm{N}=$ number of plants. & & \\
${ }^{\mathrm{y}}$ Means in column followed by the same letter are not significantly different $(P<0.05)$ \\
according to Tukey honest difference (THD) test for unequal $\mathrm{N}(P<0.05)$.
\end{tabular}

HortScience, Vol. 38(4), July 2003 
penetrans (Peng and Moens, 2002a). These conditions were used in the reported experiments on rooted hardwood cuttings. Only the inoculum density was modified here because the amount of the inoculum is critical for differentiation of the plant response among genotypes (Fassuliotis, 1985). The inoculum should be enough to establish a population (Kaplan, 1990) and be limited so that high dosages do not cause too much injury and mask potentially useful genetic material (Young, 1998). As the data obtained in the inoculum density experiment did not show differences in multiplication factor between densities ranging from 250 to 1000 and as the standard deviation was least at density $\mathrm{Pi}=500$, this latter quantity was selected for use in the screening tests.

It is accepted that experiments evaluating plant resistance to parasitic nematodes should have replicates ranging between six and ten because data are often highly variable (Kaplan, 1990). In the reported experiments we frequently observed important variation among replicates. However, less replicates with repeated screening as in reported experiments is acceptable (Kunde et al., 1968). In any case results obtained in pot experiments need to be confirmed in the field. A first selection in a limited number of pots reduces the extent of field experiments.

Nematode reproduction is the selection criterion in resistance screening tests. Reproduction on one accession can be evaluated by comparison with the reproduction on a known resistant accession (Verdejo-Lucas et al., 2000) or by assessing the total number of nematodes extracted from both soil and roots (Potter and Dale, 1994). We used the reproduction factor relating the final population density (found in the sand and the roots) to the inoculum density as suggested by Westcot and Zehr (1991).

When used for the screening of the 131 Rosa accessions, this approach allowed the observation of a large variation in host suitability. Previously reported resistance of $R$. multiflora 'K1' (Ohkawa and Saigusa, 1981; Santo and Lear, 1976; Schneider et al., 1995) and one accession of $R$. virginiana (Peng and Moens, 2002a) to $P$. penetrans was confirmed in this experiment. However, the resistance of R. eglanteria (Coolen and Hendrickx, 1972) was not confirmed in this and our previous experiment (Peng and Moens, 2002a); the species supported a nematode multiplication similar to that of R. corymbifera 'Laxa'. Rosa laevigata anemoides was the only species for which resistance was present in all of the tested plants, as none of the replicates scored a $\mathrm{Pf} / \mathrm{Pi}>1$. However, in the $0.5-\mathrm{L}$ pot experiments for which $R$. laevigata anemoides of another origin was used, the Pf/Pi averaged 1.89. Variations between different accessions were also observed in the species of $R$. glauca and $R$. virginiana. Obviously, the screening of different accessions of the same species is a valuable strategy for searching sources of resistance. The majority of Rosa accessions in our experiment supported the multiplication of $P$. penetrans. It would therefore be of great interest to evaluate the accessions for their tolerance, i.e., the ability to limit the damage caused by nematode infection.

Although screenings using a local pathogenic nematode population are of practical importance for the regional application of resistance or tolerance, results obtained with a single population can not be generalized as differences in pathogenicity were observed among populations of $P$. penetrans (Peng and Moens, unpublished data) and P. vulnus (Pinochet et al., 1993). Therefore, further screening with populations of various origins would extend the use of resistance in Rosa sp. to $P$. penetrans.

\section{Literature Cited}

Cook, R. and K. Evans. 1987. Resistance and tolerance, p. 179-231. In: R.H. Brown and B.R. Kerry (eds.). Principles and practice of nematode control in crops. Academic Press, Sydney, Australia.

Coolen, W.A. and C.J. D'Herde. 1970. Nematodes associated with glasshouse roses. In: Proc. Intl. Nematol. Symp., Warsaw, 1967. Zeszyty Problem Owe Postpoow Nauk Roleniczych. No. 92:259-266.

Coolen, W.A. and G.T. Hendrickx. 1972. Investigation on the resistance of rose rootstocks to Meloidogyne hapla and Pratylenchus penetrans. Nematologica 18:155-158.

Corbett, D.C.M. 1973. Pratylenchus penetrans, Set 2, No. 5. In: S. Willmott, P.S. Gooch, M.R. Siddiqi, and M. Franklin (eds.). C.I.H. description of plant-parasitic nematodes. Cmwlth. Instit. Helminthology, St. Albans, England.

Dubois, L.A.M., D.P. De Vries, and H. Jansen. 1990. Rose rootstock on the move. Prophyla 44:117-119.

Fassuliotis, G. 1985. The role of the nematologist in the development of resistant cultivars, p. 233240. In: J.N. Sasser and C.C. Carter (eds.). An advanced treatise of Meloidogyne Vol. 1 North Carolina State Univ. Graphics, Raleigh.

Hendrickx, G. 1995. An automatic apparatus for extracting free-living nematode stages from soil. Nematologica 41:308. (Abstr.)

Horst, R.K. 1983. Disease caused by nematodes, p. 30-32. In: R.K. Horst (ed.). Compendium of rose diseases. Amer. Phytopathol. Soc., St. Paul, Minn.

Johnson, P.W. and R.J. McClannahan. 1974. Nematode control and other effects of soil treatment of greenhouse rose beds with aldicarb and oxamyl. Plant Dis. Rpt. 58:730-732.

Kaplan, D.T. 1990. Screening resistance to Tylenchulus semipenetrans and Radopholus species, p. 51-57. In: J.L. Starr (ed.). Methods for evaluating plant species for resistance to plant-parasitic nematodes. Soc. Nematol., Hyattsville, Md.
Kunde, R.M., L.A. Lider, and R.V. Schmitt. 1968. A test of Vitis resistance to Xiphinema index. Amer. J. Enol. Viticult. 19:30-36.

Liberta, A. and M. Young. 2000. The classification of roses, p. xi-xiv. In: T. Cairns (ed.). Modern roses XI, the world encyclopedia of roses. Academic Press, New York.

O'Bannon, J.H. and A.L. Taylor. 1969. Migratory endoparasitic nematodes reared on carrot discs Phytopathology 58:385.

Ohkawa, K. and T. Saigusa. 1981. Resistance of rose rootstocks to Meloidogyne hapla, Pratylenchus penetrans and P. Vulnus. HortScience 16:590-560.

Peng, Y. and M. Moens. 1999. Effects of surface sterilisation and cold storage on in vitro behaviour of Pratylenchus penetrans. Nematology 1 : 647-653.

Peng, Y. and M. Moens. 2002a. Host suitability of rose rootstocks to root lesion nematode, Pratylenchus penetrans. Nematology 4:387-394.

Peng, Y. and M. Moens. 2002b. Tolerance of Rosa rootstocks and species to Pratylenchus penetrans. Nematology 4:395-401.

Pinochet, J., C. Fernández, D. Esmanjaud, and M. Doucet. 1993. Effect of six Pratylenchus vulnus isolates on the growth of peach-almond hybrid and apple rootstocks. J. Nematol. 25:843-848.

Potter, J.W. and A. Dale. 1994. Wild and cultivated strawberries can tolerate or resist root-lesion nematode. HortScience 1074-1077.

Richardson, P.N. and P.S. Grewal. 1993. Nematode pests of greenhouse crops and mushrooms, $\mathrm{p}$. 501-544. In: K. Evans, D.L. Trudgill, and J.M. Webster (eds.). Plant parasitic nematodes in temperate agriculture. CAB Intl., Wallingford, U.K.

Santo, G.S. and B. Lear. 1976. Influence of Pratylenchus vulnus and Meloidogyne hapla on the growth of rootstocks of rose. J. Nematol. 8:18-23.

Schneider, J.H.M., J.J. s'Jacob and P.A. van de Pol. 1995. Rosa multiflora 'Ludiek', a rootstock with resistant features to the root lesion nematode Pratylenchus vulnus. HortScience 63:37-45.

Seinhorst, J.W. 1950. De betekenis van de toestand van de grond voor het optreden van aantasting door het stengelaaltje (Ditylenchus dipsaci (Kühn) Filipjev. Tijds. Plantenz. 56:103-108.

Sher, S. A. 1959. Nematodes on ornamentals. California Agr. 13:21-22.

StatSoft. 1999. Statistica. StatSoft USA, Tulsa, Okla.

Verdejo-Lucas, S., F.J. Sorribas, J.B. Forner, and A. Alcaide. 2000. Resistance of hybrid citrus rootstocks to a Mediterranean biotype $T y$ lenchulus semipenetrans Cobb. HortScience 35:269-273.

Waeyenberge, L., A. Ryss, M. Moens, J. Pinochet, and T.C. Vrain. 2000. Molecular characterisation of 18 Pratylenchus species using rDNA restriction fragment length polymorphism. Nematology 2:135-142.

Westcott III, S.W. and E.I. Zehr. 1991. Evaluation of host suitability in Prunus for Criconemella xenoplax. J. Nematol. 23:393-401.

Young,L.D. 1998. Breeding for nematode resistance and tolerance, p. 187-207. In: K.R. Barker, GA. Pederson, and G.L. Windham (eds.). Plant and nematode interactions. Amer. Soc. Agron., Madison, Wis. 